\title{
Pengaruh Motivasi Kerja Terhadap Kinerja Guru Paud di Kecamatan Kota Tambolaka dan Loura Kabupaten Sumba Barat Daya
}

\author{
Rahel Maga Haingu ${ }^{1}$

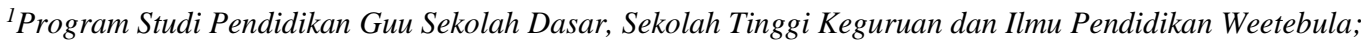

\begin{abstract}
*Corresponding Author: Rahel Maga Haingu, Program Studi Pendidikan Guu Sekolah Dasar, Sekolah Tinggi Keguruan dan Ilmu Pendidikan Weetebula; Email:

rahel_haingu@yahoo.co.id.
\end{abstract}

\begin{abstract}
Abstrak: Penelitian ini bertujuan untuk mengetahui pengaruh motivasi kerja terhadap kinerja guru PAUD yang menagajar di TK Kecamatan Kota Tambolaka dan Loura. Penelitian ini merupakan penelitian kuantitatif jenis regresi sederhana. Populasi dalam penelitian berjumlah 51 orang guru PAUD di TK. Instrumen yang digunakan dalam penelitian ini adalah kuesioner/angket. Teknik analisis data yang digunakan adalah regresi linear sederhana. Hasil penelitian menunjukkan terdapat pengaruh positif dan signifikan faktor motivasi kerja terhadap kinerja guru PAUD di TK sesuai dengan koefisien regresi sebesar 0,633 yang bernilai positif.
\end{abstract}

Kata kunci: Kinerja guru PAUD, motivasi kerja

\section{Pendahuluan}

Salah satu unsur keberhasilan sebuah pendidikan yang berkualitas adalah pendidik. Pendidik merupakan ujung tombak dari keberhasilan terlaksananya suatu proses pembelajaran. Penyelenggaraan pendidikan di sekolah yang melibatkan guru sebagai pendidik dan siswa sebagai peserta didik, diwujudkan dengan adanya interaksi belajar mengajar atau proses pembelajaran. Proses pembelajaran dilaksanakan oleh seorang pendidik/guru.

Undang-Undang No. 14 tahun 2005 tentang guru dan dosen dalam Bab II Pasal 2 dinyatakan bahwa guru mempunyai kedudukan sebagai tenaga profesional khususnya pada jalur formal untuk jenjang pendidikan anak usia dini.

Arida (2014) mengatakan "guru merupakan unsur manusiawi yang sangat menentukan keberhasilan pendidikan". Ungkapan tersebut menandakan bahwa pendidikan memiliki pengaruh, bantuan atau tuntutan yang diberikan oleh orang yang bertanggung jawab kepada anak didik (Ahmadi \& Uhbiyati, 2003: 71).

Seiring dengan perkembangan ilmu pengetahuan dan teknologi, tugas, peran dan tanggung jawab guru dalam dunia pendidikan semakin tinggi. Guru dituntut untuk mampu menjalankan tugas dan fungsinya sebagai pendidik, seperti yang tertuang dalam UU No. 20 tahun 2003 dan UU No. 14 tahun 2005 yang menyatakan bahwa peran guru adalah sebagai pendidik, pengajar, pembimbing, pengarah, pelatih, penilai, dan pengevaluasi dari peserta didik. Tuntutan tersebut menjadi satu kendala yang harus dilaksanakan oleh seorang pendidik untuk menjadi guru yang profesional. Guru yang profesional harus memiliki berbagai keterampilan, kemampuan khusus, mencintai pekerjaannya, menjaga kode etik guru dan lain sebagainya (Yamin, 2007: 23). Guru sebagai sosok profesional harus memiliki kompetensi dan kinerja yang sesuai dengan tuntutan pekerjaannya sehingga mempunyai kewenangan yang jelas dalam peningkatan mutu masyarakat indonesia (Mulyasa, 2013: 30).

Joyce (2014) menyatakan bahwa "Professional conduct is critical to effective work performance of all employees including teachers". Guru melakukan tugas profesionalnya yang dimulai dari berbagai tugas terkait dengan administrasi, juga berbagai tugas yang terkait dengan tugas mengajar dan menilai hasil pembelajaran yang dilakukan (Uno \& lamatenggo, 2016: 48). Melalui pembelajaran peserta didik dapat belajar dengan baik. Dengan kata lain pembelajaran pada hakikatnya merupakan proses komunikasi antara peserta didik dengan pendidik serta antarpeserta didik dalam rangka perubahan sikap (Yamin \& Maisah, 2009: 107 \& 123). Guru yang bertugas 
sebagai pengelola pembelajaran dituntut memenuhi standar kompetensi dan profesionalismenya. Guru dalam melaksanakan tugasnya harus selalu bersikap terbuka, kritis dan skeptis untuk mengaktualisasi penguasaan isi bidang studi, pemahaman karakteristik peserta didik dan melakonkan pembelajaran yang mendidik (Mulyasa, 2013: 6 \& 7). Penelitian Arida (2014: 4) menyatakan bahwa peran guru menjadi salah satu komponen yang penting dan strategis melalui kinerjanya. Kinerja guru sangat penting dalam mewujudkan tujuan pendidikan nasional dan menentukan tinggi rendahnya mutu pendidikan, akan tetapi kinerja guru ini banyak dipengaruhi oleh berbagai faktor baik dari dalam maupun dari luar individu yang bersangkutan.

Kinerja mengandung makna hasil kerja, kemampuan, prestasi atau dorongan untuk melaksanakan suatu pekerjaan. Keberhasilan individu atau organisasi dalam mencapai target atau sasaran tersebut merupakan kinerja. Kinerja adalah hasil kerja sesorang dalam suatu periode tertentu yang dibandingkan dengan beberapa kemungkinan, misalnya standar target, sasaran atau kriteria yang telah ditentukan terlebih dahulu (Supardi2013: 4647). Berdasarkan Peraturan Menteri Pendidikan Nasional Republik Indonesia Nomor 16 Tahun 2007 tentang Standar Kualifikasi Akademik dan kompetensi guru dijelaskan bahwa Standar Kompetensi Guru dikembangkan secara utuh dari 4 kompetensi utama, yaitu: (1) kompetensi pedagogik, (2) kompetensi kepribadian, (3) kompetensi sosial, dan (4) kompetensi profesional. Keempat kompetensi tersebut terintegrasi dalam kinerja guru. Dengan demikian dapat disimpulkan bahwa kinerja guru merupakan bagian dari kompetensi guru yang terintegrasi dalam pelaksanaan proses pembelajaran. Hasil Uji Kompetensi Guru (UKG) pada tahun 2015 untuk seluruh provinsi di Indonesia, menghasilkan bahwa guru yang berhasil memperoleh nilai UKG tahun 2015 tertinggi adalah guru SMA dari Papua Barat. Guru tersebut memperoleh nilai UKG 93,33 dalam mata pelajaran Bahasa Jerman. Namun ternyata ada juga yang memperoleh nilai lebih dari itu, yakni guru Cirebon dengan nilai 96,67.

Data uji kompetensi guru (UKG) sementara untuk provinsi Nusa Tenggara Timur, yang dikemukakan oleh kepala LPMP Nusa Tenggara Timur (NTT) Minhajul Ngabidin, menyatakan bahwa hasil sementara uji kompetensi guru (UKG) tahun 2016 untuk NTT berada pada urutan ke 23 dari 34 provinsi yang ada di Indonesia. Adapun hasil rata-rata UKG tiap jenjangnya berturut-turut untuk guru TK paling tinggi rata-ratanya diikuti oleh guru SMA, guru SMK, guru SMP, guru SD, dan paling akhir adalah guru SLB. Sedangkan dari sisi usia nilai tertinggi dicapai oleh guru dengan kelompok usia 30 tahun sampai 40 tahun, sedangkan kelompok usia 41 tahun, 50 tahun, 51 tahun sampai 56 tahun mengalami penurunan. Raddana (2013: 229) menyatakan bahwa kinerja guru secara fundamental ditentukan oleh keahlian dan kemampuan guru yang bersangkutan. Hal senada didukung oleh hasil penelitian Suryani (2013: 90) menyatakan bahwa aspek kinerja guru merupakan aspek penting yang perlu diperhatikan. Menjaga dan mengupayakan guru supaya memiliki kinerja yang tinggi dan mutlak diperlukan untuk menciptakan sumber daya manusia yang berkualitas.

Berdasarkan uraian di atas dapat disimpulkan bahwa pendidik sangat berperan penting dalam sebuah pendidikan dan memiliki peran yang sangat fundamental dalam melaksanakan kegiatan proses belajar mengajar. Akan tetapi pada kenyataan masih banyak masalah yang menglingkupi para pendidik terkhususnya pendidik di pendidikan anak usia dini, baik dilihat dari kuantitas maupun dari kualitasnya.

Untuk meningkatkan mutu pendidikan pendidik di pendidikan anak usia dini beberapa kegiatan telah dilakukan dengan mengadakan pelatihan seperti pelatihan guru PAUD di kabupaten Sumba Barat Daya, provinsi Nusa Tenggara Timur pada tanggal 21 april 2016 dan kegiatan seminar yang diadakan oleh Sekolah Tinggi Keguruan dan Ilmu pendidikan Weetebula yang disampaikan oleh Dr. Slamet Suyanto tentang "pembelajaran dan pengembangan kurikulum PAUD" pada tanggal 23 Juli 2016, yang dihadiri oleh para guru PAUD Sesumba (Sumba Timur, Sumba Tengah, Sumba Barat dan Sumba Barat Daya). Peningkatan kompetensi guru seperti pelatihan, perbaikan sarana dan prasarana serta peningkatan mutu manajemen sekolah dilakukan dengan baik. Namun pada kenyataannya, strategi yang dilakukan untuk meningkatkan mutu tenaga pendidik belum menunjukkan peningkatan yang berarti. Faktor pencapaian ini sangat kental dan sangat kritis hubungan dengan profesional kerja guru, kompetensi, motivasi, dan adanya perhatian pemerintah, disisi lain kondisi kerja yang tidak sesuai dengan harapan, juga dapat menjadi kendala 
dalam peningkatan kinerja guru. Agustina \& Indrawati (2006) menyatakan bahwa faktor yang mempengaruhi kinerja guru adalah faktor pengetahuan/kemampuan, keterampilan dan motivasi, mempunyai pengaruh yang sangat kuat terhadap kinerja guru. Sedangkan faktor yang paling dominan mempengaruhi kinerja guru adalah faktor motivasi.

Sedangkan Raddana (2013) menyatakan bahwa peningkatan kinerja guru tidak timbul secara langsung sebagai hasil dari sertifikasi guru tetapi kinerja guru akan meningkat apabila didahului peningkatan motivasi kerja guru. Beberapa faktor yang mempengaruhi kinerja guru yaitu, motivasi kerja, kepuasan kerja, sertifikasi guru dan kompetensi guru. Sejalan dengan penelitian Ali, et al (2016:24) mengatakan bahwa there is a significant relationship between teacher motivation, job satisfaction and school performance. Halsenada di sampaikan oleh Chux, et al (2013: 838) highly motivated educators experience job satisfaction; and also perform better than their poorly motivated counterparts. In terms of motivation, the results further suggest that a mix of intrinsic and extrinsic factors tend to exert influence on the educators motivation.

Dari uraian diatas dapat diketahui bahwa banyak faktor yang mempengaruhi kinerja guru, sehingga penelitian ini dimaksudkan untuk mengetahui kinerja guru PAUD di TK kecamatan Kota Tambolaka dan Loura kabupaten Sumba Barat Daya. Ditinjau dari faktor-faktor yang mempengaruhi salah satunya adalah faktor motivasi kerja. Motivasi kerja merupakan keinginan seseorang untuk mempertanggungjawabkan pekerjaan yang sudah diembankan kepadanya. Motivasi kerja sangat mempengaruhi kinerja guru. Pada dasarnya kinerja guru dipengaruhi oleh faktor dari dalam diri guru itu sendiri yaitu bagaimana guru bersikap dalam melaksanakan pekerjaannya sebagai pendidik seperti motivasi kerja yang dipengaruhi oleh ketaatan pada peraturan dan kemauan guru itu sendiri dalam menjalankan tugasnya.

\section{Metode Penelitian}

Sesuai dengan permasalahannya, jenis penelitian yang digunakan adalah penelitian regresi sederhana. Sedangkan metode pendekatan yang digunakan adalah metode kuantitatif. Penelitian ini dilakukan di provinsi Nusa Tenggara Timur
Kabupaten Sumba Barat Daya. Waktu penelitian bulan Maret 2017 sampai dengan April 2017.

\section{Subjek Penelitian}

Populasi dalam penelitian ini adalah guruguru PAUD di TK Kabupaten Sumba Barat Daya. Adapun jumlah pendidik untuk Kota Tambolaka untuk guru PAUD Taman Kanak-Kanak (TK) berjumlah 32 orang guru, sedangkan untuk kecamatan Laura berjumlah 19 orang guru, sehingga dapat disimpulkan bahwa populasi dari penelitian ini berjumlah 51 orang guru PAUD di TK Kabupaten Sumba Barat Daya.

\section{Variabel PenelitiandanTeknik Pengumpulan Data}

Variabel dalam penelitian ini adalah motivasi kerja $(\mathrm{X})$, dan variabel terikatnya adalah kinerja guru (Y). Teknik pengumpulan data yang digunakan adalah angket. Instrumen yang gunakan kuesioner dalam bentuk pernyataan dan dilengkapi dengan alternatif jawaban. Setiap pernyataan, terdiri dari lima jawaban pilihan, sebagai berikut: a) TP:Tidak Pernah; b) JR: Jarang; c) KK: KadangKadang; d) SR: Sering; dan e) SL: Selalu. Atau a) STS: Sangat Tidak Setuju; b) TS: Tidak Setuju; c) KS: Kurang Setuju; d) S: Setuju; dan e) SST: Sangat Setuju.

\section{Teknik Analisis Data}

Analisis data menggunakan; (1) Uji Persyaratan Analisis regresi. Untuk analisis persyaratan regresi dengan uji normalitas, uji linearitas, uji multikolinearitas,dan uji heteroskedastisitas. Semua uji asumsi tersebut memenuhi syarat perhitungan regresi; (2) Uji Hipotesis menggunakan analisis regresi sederhana. Persamaan regresi linear sederhana adalah $\hat{Y}=a+$ b X.adapun hipotesisnya adalah: H0 : tidak ada pengaruh faktor motivasi kerja terhadap kinerja guru PAUD dan Ha: ada pengaruh faktor motivasi kerja terhadap kinerja guru PAUD.

\section{Hasil Penelitian Dan Pembahasan Hasil Penelitian}

Berdasarkan tabel 1 menunjukan koefisien korelasi (R) sebesar 0,528. Koefisien korelasi tersebut menunjukkan adanya hubungan yang signifikan motivasi kerja dengan kinerja guru. Koefisien (R2) sebesar 0,279 koefisien determinasi menunjukkan kinerja guru dijelaskan oleh motivasi 
kerja sebesar $27,9 \%$. Koefisien regresinya pada tabel 2 dapat di lihat tingkat signifikansi pengaruh motivasi kerja terhadap kinerja guru atau t hitug sebesar 4.354 lebih besar dari t tabel 2.010. Arah regresinya sebesar 0,633 . Dengan demikian arah regresinya adalah positif. Selanjutnya dapat dideskripsikan persamaan regresi yaitu $\ddot{\mathrm{Y}}=\mathrm{a}+$ $\mathrm{bX1}$. Jika $\mathrm{a}=47.890$ dan $\mathrm{b}=0,633$ maka persamaan regresi motivasi kerja (b1X1) yaitu $\ddot{Y}=$ $47.890+0,633 \mathrm{X} 1$ artinya semakin bertambah nilai motivasi kerja (X1), semakin bertambah pula nilai kinerja guru (Y).

Tabel 1 Korelasi Motivasi Kerja

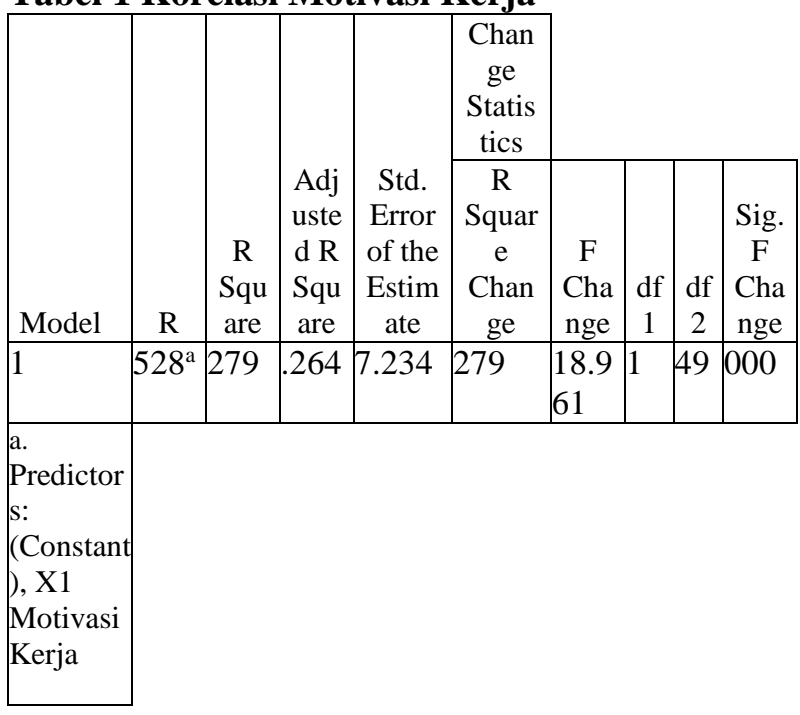

Tabel 02. Koefisien Regresi Parsial

\begin{tabular}{|c|c|c|c|c|c|c|}
\hline \multirow{2}{*}{\multicolumn{2}{|c|}{ Model }} & \multicolumn{2}{|c|}{$\begin{array}{l}\text { Unstandardized } \\
\text { Coefficients }\end{array}$} & \multirow{2}{*}{\begin{tabular}{|l}
$\begin{array}{l}\text { Standardized } \\
\text { Coefficients }\end{array}$ \\
Beta \\
\end{tabular}} & \multirow{2}{*}{$\mathrm{T}$} & \multirow{2}{*}{ Sig. } \\
\hline & & B & \begin{tabular}{|l|} 
Std. \\
Error
\end{tabular} & & & \\
\hline \multirow[b]{2}{*}{1} & $\begin{array}{l}\text { (Const } \\
\text { ant) }\end{array}$ & 47.890 & 9.137 & & 5.241 & 000 \\
\hline & $\begin{array}{l}\text { X1 } \\
\text { Motiv } \\
\text { asi } \\
\text { Kerja }\end{array}$ & 633 & 145 & 528 & 4.354 & 000 \\
\hline
\end{tabular}

\section{Pembahasan}

Berdasarkan hasil analisis data penelitian faktor motivasi kerja (X) arah regresi atau tingkat signifikansi pengaruh motivasi kerja terhadap kinerja guru sebesar 4.354 dan arah regresinya sebesar 0,633 yang berarti bernilai positif. Artinya semakin bertambah nilai motivasi kerja $(\mathrm{X})$, maka semakin bertambah pula nilai dari variabel kinerja guru (Y).

Dari hasil analisis di atas, dalam penelitian ini sejalan dengan hasil penelitian Sugiarto (2012) yang menyimpulkan bahwa motivasi kerja dan lingkungan kerja mempengaruhi variabel prestasi kerja pegawai pada Dipenda Provinsi Jawa Timur berpengaruh positif dan signifikan terhadap prestasi kerja/kinerja guru di Provinsi Jawa Timur. Selain itu dalam peneltian Connie (2013: 138) juga menyimpulkan bahwa motivasi kerja guru fisika berpengaruh langsung positif terhadap kinerja guru fisika.

Penelitian Harun \& Erkan (2014) menjelaskan bahwa "motivating teachers should be an essential part of any educational system, so that students can perform better and so that we, as the larger society, may attain a better future". Juga dalam penelitian Rahadian dan Endra (2016: 92) menyimpulkan bahwa motivasi kerja mempunyai pengaruh positif terhadap kinerja karyawan pada UMKM di desa Wisata Bobung Gunungkidul Yogyakarta

\section{Kesimpulan dan Saran}

\section{Kesimpulan}

Berdasarkan hasil analisis data dan pembahasannya, maka dapat dibuat beberapa kesimpulan,Terdapat pengaruh positif dan signifikan motivasi kerja terhadap kinerja guru PAUD di TK Kabupaten Sumba Barat Daya kecamatan Kota dan kecamatan Laura sesuai dengan koefisien regresi sebesar 0,633 yang benilai positif.

\section{Saran}

Agar pendidikan anak usia dini ke depan semakin lebih di perhatikan dengan baik, agar menghasilkan tenaga pendidik yang profesional dalam melaksanakan tugas dan tanggung jawabnya sebagai pendidik.

\section{Daftar Pustaka}

Agustina, H. \& Indrawati Y. (2006). Faktor-Faktor Yang Mempengaruhi Kinerja Guru Matematika Dalam Pelaksanaan Kurikulum Berbasis Kompetensi (KBK) Pada Sekolah Menengah Atas Kota Palembang. Jurnal Manajemen dan Bisnis Sriwijaya (JMBS) / Vol 4/No 7/Hal 176/2006/ISSN 1412-4521. 
Arida, F. (2014). Faktor-Faktor Yang Mempengaruhi Kinerja Guru Dalam Menjalankan Tugas Di SDN 001 Teratak Kecamatan Rumbiojaya. Jurnal Fakultas Ilmu Sosial dan Politik Universitas Riau, Jurusan Sosiologi - Prodi Sosiologi (Jom FISIP) Volume 1 No. 2 - Oktober 2014. Hal 5.

Ahmadi, H. A. \& Uhbiyati, N. (2003). Ilmu pendidikan. Jakarta: Rineka Cipta.

Ali, Y. S. A., Abdulkadir, M. D. \& Ali A. A. (2016). Teacher Motivation and School Performance, the Mediating Effect of Job Satisfaction: Survey from Secondary Schools in Mogadishu. International Journal Of Education And Social Science. Vol. 3 No. 1; January 2016.

Connie. (2013). The Influence of Professional Competence, Work Motivation and Innovativeness on The Performance of Physics Teacher. 2nd International Seminar on Quality and Affordable Education (ISQAE 2013).

Chux, G. I. Et. Al (2013). Teacher Job Satisfaction And Learner Performance In outh Africa. Journal of Economics and Behavioral Studies Vol. 5, No. 12, pp. 838-850, Dec 2013 (ISSN: 2220-6140).

http://kupang.tribunnews.com/2016/01/29/hasilukg-ntt-tempati-urutan-ke-23-nasional (senin, 03 oktober 2016. Jam 12.01)

Harun, G. \& Erkan, A. (2014). The Intrinsic And Extrinsic Factors For Teacher Motivation. journal University, Department of Sociology and Social Work and Holt Romania Foundation (Sociology and Social Work Domains), ISSN: 15845397.Revistade cercetare [interven]ie sociaA, 2014, vol. 47, pp. 291-306.

Joyce, N. (2014). Motivational Factors Affecting High School Teachers' Professional Conduct and Work Performance: A Case of Public High Schools in Nairobi City. International Journal of Humanities and
Social Science.Vol. 4 No. 3; February 2014.

Mulyasa. (2013). Uji Kompetensi dan Penilaian Kinerja Guru. Bandung: PT. Remaja Rosdakarya

Raddana. (2013). Faktor-Faktor yang Mempengaruhi Kinerja Guru SMA Negeri Di Nusa Tenggara Barat (NTB). DIA, Jurnal Administrasi Publik Desember 2013, Vol. 11, No. 2, Hal. 226 $-236$.

Rahadian, F. \& Endra, M. S. (2016). Pengaruh kompensasi, kepuasan kerja, motivasi kerja dan gaya kepemimpinan terhadap kinerja karyawan. Jurnal Nominal / Volume V Nomor 2.

Supardi. (2013). Kinerja guru. Jakarta: Rajawali Pers.

Sugiarto. (2012). Pengaruh Motivasi Kerja Dan Lingkungan Kerja Terhadap Prestasi Kerja Pegawai Pada Dipenda Provinsi Jawa Timur. Jurnal "Otonomi" Vol. 12 No.2. April 2012

Suryani, D. P. (2013). Pengaruh motivasi kerja, kepuasan kerja, kepemimpinan kepala sekolah menurut persepsi guru dan iklim sekolah terhadap kinerja guru Ekonomi SMP negeri di kabupaten Wonogiri. Jurnal pendidikan insan mandiri: Vol.1 No.1 (2013).

Uno, H. B. \& Lamatenggo, N. (2016). Tugas guru dalam pembelajaran. Jakarta: Bumi Aksara

Yamin. M. (2007). Sertifikasi profesi keguruan di indonesia. Jakarta Pusat: Gaung Persada Press

Yamin, M.M. \& Maisah. (2009). Manajemen pembelajaran kelas (strategi meningkatkan mutu pembelajaran). Jakarta: GP Press 